\title{
Transient Hyperglycemia in Neonate: A Case Report
}

SK Banik ${ }^{1}$, S Snigdha ${ }^{2}$, Z Islam $^{3}$, N Nahar ${ }^{4}$.

\begin{abstract}
:
Hyperglycemia has become a significant risk factor for morbidity and mortality as smaller and more fragile infants survive during the neonatal period. Historically, hyperglycemia has been attributed to excessive IV glucose infusion. More recent studies indicate that physiologic and biochemical mechanisms, leading to excess glucose production, insulin resistance, or glucose intolerance, underlie the development of hyperglycemia in preterm infants and sometimes inhibit efforts to maintain normal glycemia in the neonate. The sequelae of these disturbances in glucose metabolism are extensive. Efforts to prevent hyperglycemia should include general measures to improve the health of the infant and attempts to treat pathophysiologic conditions and diseases. ${ }^{13}$
\end{abstract}

\section{Introduction:}

Hyperglycemia in neonates is defined as serum glucose (capillary) level more than $125 \mathrm{mg} \%$. This may occur secondary to a variety of causes in the neonatal period. It is however important to distinguish transient diabetes mellitus of the neonate from other causes of hyperglycemia in the newborn period. Recently, we had under our care in BIRDEM Hospital Dhaka, a case of neonatal hyperglycemia which is being reported here.

\section{Case report:}

A 4 days old child, born of a full term normal delivery and weighing $2.2 \mathrm{~kg}$. presented with loose motions and vomiting for 1 day prior to admission. The child also had oliguria for 12 hours prior to admission. The child was a first born, uncomplicated home delivery and had cried immediately after birth. Antenatal history was uneventful. On admission, the child was hypothermic, and in grade II dehydration with acidotic breathing. Abdomen was distended with absent persistalsis, and palpable lumps. Investigations revealed haemoglobin $16 \mathrm{gm} \%$, total W.B.C count $4,400 / \mathrm{cmm}$ with polymorphs $75 \%$, lymphocytes $10 \%$ and band forms $15 \%$; serum sodium $160 \mathrm{meq} / \mathrm{L}$, potassium 6.7 meq./L. and chlorides 104 meq./L. Blood sugar was $495 \mathrm{mg} \%$, and blood gases were as follows: $\mathrm{pH}$ 6.92, HCO3 6.6 meq/L, PCO2 34.3 mm Hg, PO2 71.5 mm

1. Dr. Sukhamoy Kangsha Banik, Assistant Professor, Department of Paediatric Nephrology, National Institute of Kidney Diseases and Urology, Dhaka.

2. Dr. Snigdha Sarker, MO, Dept. of Respirator Medicine, NIDCH, Mohakhali, Dhaka.

3. Dr. Md. Zakirul Islam, Asst. Professor of Pediatrics, SSMC,Dhaka.

4. Dr. Nazmun Nahar, Prof.of Paediatrics and Academic Director, Ibrahim Medical College and BIRDEM Hospital, Dhaka.

\section{Corresponding Author:}

Dr. Sukhamoy Kangsha Banik, Assistant Professor, Department of Paediatric Nephrology, National Institute of Kidney Diseases and Urology, Dhaka.
$\mathrm{Hg}$ and $\mathrm{O} 2$ saturation $88.4 \%$. Urine showed the presence $(+++)$ of reducing substances (confirmed as glucose). Ketones, albumin, RBcs and WBcs were absent in the urine. Stool examination revealed Gram negative bacilli on smear, 15-20 pus cells/HPF and RBCs were absent. Blood and stool culture grew Klebsiella organisms sensitive to amikacin. The child was treated with IV fluids to correct his dehydration, sodibicarb to combat acidosis, and ceftazidim and amikacin. Repeat blood sugar done after 4 hours was $390 \mathrm{mg} \%$ and $130 \mathrm{mg} \%$ after 12 hours.Nasogastrictube was not inserted. Repeat blood gases and serum electrolytes were normal after 22 hours. The child died 30 hours after admission. Post-mortem showed perforation $2 \mathrm{~cm} \times 2 \mathrm{~cm}$ in the anterior wall of stomach. Adrenals, pancreas and kidney showed hemorrhagic lesions suggestive of septicemia.

\section{Discussion:}

There are various causes of neonatal hyperglycemia. Transient neonatal diabetes mellitus: (TNDM ) This is a discreet clinical entity that simulates diabetes mellitus has been described in small for gestational age (SGA) babies during the first six weeks of life. Such states are also referred to as congenital neonatal pseudodiabetis, paradiabetes mellitus infantum or congenital temporary diabetes. ${ }^{1,2}$ The first patient identified as having this syndrome was the son of a physician who presented with 'honeyed napkins', ${ }^{3}$ polydypsia, polyphagia, polyuria, dry skin after birth and the child died at 6 months of age because of urinary tract infection. ${ }^{4}$ Characteristically, ketonuria is minimal or absent, but hyperglycemia, glycosuria and dehydration may be severe. The majority of these patients

have temporary type of diabetes from which they recover, a few ultimately develop permanent juvenile diabetes mellitus. ${ }^{5}$ Transient neonatal diabetis mellitus is uncommon and the exact incidence is unknown. ${ }^{4}$ McDonald found 41 cases in world literature in 1974, 31 being SGA. ${ }^{6}$ This syndrome is usually sporadic in occurrence, though congenital or familial forms may occur. $^{7}$ Family history of diabetes is present in $35 \%$ cases, ${ }^{4}$ no sex prediliction has be noted in the cases reported. This condition should be thought of in a full term, (small for gestational age) child who presents with features of dehydration and wasting in presence of normal intake and absence of vomiting and loose motions. The infants are classically described as having peculiar pallor, aged appearance and open eyed alert facies, ${ }^{8}$ evidence of infection with fever and polyuria and sudden weight loss are also noted; ${ }^{4}$ common age of presentation is 2 weeks with a range of 1 day to 6 weeks. ${ }^{7}$ The diagnosis is confirmed by documenting hyperglycemia which can range anywhere from $240-2300 \mathrm{mg} \%,{ }^{4}$ glycosuria present in all cases and minimum to absent ketosis. Transient 
actonuria has been reported in 33\% cases and metabolic acidosis in $80 \%$ cases. ${ }^{4}$ Serum insulin levels are either absolutely or relatively low for the corresponding blood sugar level. In permanent juvenile diabetes mellitus serum insulin are persistently low $<10 \mu \mathrm{U} / \mathrm{ml}^{8,9,10,11}$ The exact mechanism to explain this entity is not known but there are several postulates. ${ }^{2,7,9,11,12}$ They include transient hypothalamic imbalance, infection, adrenocortical disturbance, insulin resistance, immaturity of hepatic gluconeogenetic enzymes. However, the most accepted ones are hypoinsulinism with $\beta$ cell hypoplasia ${ }^{8}$ and temporary delay in $\beta$ cell maturity. ${ }^{13}$

Treatment consists of rapid correction of dehydration and metabolic acidosis and insulin in the dose of 1-3 $\mathrm{u} / \mathrm{kg} / \mathrm{day}$ or 2-8 $\mathrm{u} /$ day. ${ }^{4}$ Some patients may not require insulin, but those who do, respond dramatically. Later on the dose of insulin should be gradually tapered off with periodic blood sugar monitoring. Glycosuria may persist for as long as 18 months or may subside in 2 weeks. ${ }^{4}$ On follow up, $10 \%$ of these patients have mental retardation and other neurological sequale. ${ }^{10}$ These could be due to either the prolonged hyperosmolar state or hypoglycemia following insulin. 8,10 Some patients have been successfully treated with chlorpropamide after initial control with insulin. ${ }^{6}$ Repeated insulin levels are necessary to distinguish transient from permanent diabetes mellitus.

\section{Hyperosmolarity:}

Hyperosmolarity is associated with wide variations in blood sugar. Even CSF sugar may be high, well over 100 $\mathrm{mg} \%$. This may occur due to hypernatremic dehydration following gastroenteritis ${ }^{14}$ or due to hyperosmolar feeds. ${ }^{15}$ The mechanism may be due to a stress reaction modified by hypernatremia. ${ }^{14}$ Therapy consists of adequate hydration.

Convulsions

Convulsions occasionally produce hyperglycemia. This is mediated by liberation of catecholamines. Blood sugar rises just after or during fits. Spirer et al, ${ }^{16}$ in a study of 39 children, found that the levels came down from 150-200 mg $\%$ to $41-105 \mathrm{mg} \%$ in 2 hours. ${ }^{16}$

Intracranialhemorrhage

Some authors have attributed transient diabetes to intracranial hemorrhage. However, cerebral damage has never been proved to be the only cause of diabtes mellitus. It may produce hyperglycemia and glycosuria but it is always of a short duration. ${ }^{10}$

\section{Infection}

Septic babies and sick neonates may have hyperglycemia. This may be due to altered renal threshold with decreased utilisation of glucose in the presence of increased circulating insulin. ${ }^{17}$ It may also be due to increased levels of steroid hormones and catecholamines.

Very low birth weight babies(VLBW) VLBW babies have deranged carbohydrate metabolism. Many cases have been described where they develop hypoglycemia on 3rd or 4th day. Following treatment with glucose they develop a state of transient diabetes mellitus after 3-6 days which required insulin therapy for periods ranging from 14-40 days. ${ }^{18,19}$ Thus, these infants are precariously placed as far as their carbohydrate metabolism is concerned.

Hyper-adrenocorticism

Hyperglycemia may be present due to increased cortisol levels. ${ }^{10}$

Idiopathic:

In some cases the cause may not be evident even after a complete workup. ${ }^{12}$

In an older child salicylate poisoning, burns and acute pancreatitis should also be considered in the differential diagnosis of a child with hyperglycemia. At times, it becomes difficult to ascertain the cause of hyperglycemia as is illustrated by the present case. From the clinical and laboratory data in the present case, it was evident that the child had gastroenteritis with hypernatramic dehydration with pre-renal failure and septicemia. Also, the child had significant hyperglycemia. This was possibly due to hypernatremia and septicemia both of which are known to give rise to hyperglycemic states. We were obviously not dealing with transient neonatal diabetes mellitus because the child was sick, had hypernatremia and oliguria. TNDM babies are usually alert, active and otherwise well but emaciated. However, in doubtful cases serum insulin can be of value, in TNDM it being low to low normal for the corresponding blood sugar level, whereas in sepsis it is normal to high. In our case we did not feel the need for doing serum insulin levels in view of the clearcut clinical picture. From the therapeutic angle such babies do not require insulin because of insulin resistance. Treatment of underlying etiology is sufficient to reduce the blood sugar level.

\section{Acknowledgement:}

We wish to thank Prof.Nazmun Nahar Professor Dept. of paediatrics and Neonatology, BIRDEM Dhaka for allowing us to publish this article.

\section{References:}

1. Engleson, G. and Zetterqvist, P.: Congenital diabetes mellitus and neonatal pseudodiabetes mellitus. Arch. Dis. Child, 32: 193-196, 1957.

2. Coffey, J. D., Womack, N. C. and Miss, N.: Transient neonatal diabetes mellitus in half sisters. Amer. J. Dis. Child, 113: 480-482, 1967.

3. Gerrard, D. M. and Chin, W. P.: The syndrome of transient diabetes, J. Pediatr., 61: 93-93, 1952.

4. Cornblath, M. and Schwarts, R.: Transient neonatal diabetes mellitus. In, "Disorders of Carbohydrate Metabolism in Infancy." 2nd edition, W. B. Saunders Company, Philadelphia, 1976, pp. 218-227.

5. Merchant, R. M., Irani, A. and Nagar, P.: Transient diabetes mellitus in early infancy. Ind. Pediatr., 22: 529-532, 1985. 
6. Craig, O.: Transient neonatal diabetes. In, "Childhood Diabetes and Its Management." 2nd Edition, Butterworth \& Co., London, 1981, pp. 193-195.

7. Ferguson, A. W. and Milner, R. D. G.: Transient neonatal diabetes mellitus in sibs. Arch. Dis. Child, 45: 80-83, 1970.

8. Hutchinson, J. H., Keay, A. J. and Kerr, M. M.: Congenital temporary diabetes mellitus. Brit. Med. J., 2: 436-440, 1962.

9. Ferguson, I. C.: Neonatal hyperglycemia, a case report with plasma insulin studies. Arch. Dis. Child, 42: 509-513, 1967.

10. Gentz, J. C. H. and Cornblath, M.: Transient diabetes of newborn. Adv. Pediatr., 16: 345-363, 1969.

11. Schiff, D., Colle, E. and Stern, L.: Metabolic and growth patterns, in transient neonatal diabetes. New Engl. J. Med., 287: 119-122, 1972.

12. Lewis, Sheila, R. and Mortimer, Patricia, E.: Idiopathic neonatal hyperglycemia. Arch. Dis. Child, 39: 618-624, 1964.

13. Pagliara, A. S., Karl, I. E. and Kipnis, D. B.: Transient neonatal diabetes-delayed maturation of pancreatic beta cells. J. Pediatr., 82: 97-101, 1973.
14. Stevenson, R. E. and Bowyer, F. P.: Hyperglycemia with hyperosmolar dehydration in non diabetic infants. J. Pediatr., 77: 818-823, 1970.

15. Jung, A. L., Done, A. K.: Extreme hyperosmolality and transient diabetes due to inappropriately diluted infant formula. Amer. J. Dis. Child, 118: 859-863, 1969.

16. Spirer, Z., Weisman, J., Yurman, S. and Bogair, N.: Hyperglycemia and convulsions in children. Arch. Dis. Child, 49: 811-813, 1974.

17. Gutberlt, R. L. and Santos, A. G.: Altered carbohydrate metabolism in sick premature. Pediatr. Res., 7: 312-313, 1973.

18. Chance, G. W. and Bower, B. D.: Hypoglycemia and temporary hyperglycemia in infants of low birth weight for maturity. Arch. Dis. Child., 41: 279-285, 1966.

19. Osborne, G. R.: Congenital diabetes. In, Paediatric Pathology Club Proceedings of the Tenth Annual Meeting. Arch. Dis. Child, 40: 332-333, 1965. 